\title{
Topical Ocular Delivery of NSAIDs
}

\author{
Munish Ahuja, ${ }^{1}$ Avinash S. Dhake, ${ }^{2}$ Surendra K. Sharma, ${ }^{1}$ and Dipak K. Majumdar ${ }^{3,4}$
}

Received 21 October 2007; accepted 15 February 2008; published online 25 April 2008

\begin{abstract}
In ocular tissue, arachidonic acid is metabolized by cyclooxygenase to prostaglandins which are the most important lipid derived mediators of inflammation. Presently nonsteroidal anti-inflammatory drugs (NSAIDs) which are cyclooxygenase (COX) inhibitors are being used for the treatment of inflammatory disorders. NSAIDs used in ophthalmology, topically, are salicylic-, indole acetic-, aryl acetic-, aryl propionicand enolic acid derivatives. NSAIDs are weak acids with pKa mostly between 3.5 and 4.5 , and are poorly soluble in water. Aqueous ophthalmic solutions of NSAIDs have been made using sodium, potassium, tromethamine and lysine salts or complexing with cyclodextrins/solubilizer. Ocular penetration of NSAID demands an acidic ophthalmic solution where cyclodextrin could prevent precipitation of drug and minimize its ocular irritation potential. The incompatibility of NSAID with benzalkonium chloride is avoided by using polysorbate 80 , cyclodextrins or tromethamine. Lysine salts and $\alpha$-tocopheryl polyethylene glycol succinate disrupt corneal integrity, and their use requires caution. Thus a nonirritating ophthalmic solution of NSAID could be formulated by dissolving an appropriate water-soluble salt, in the presence of cyclodextrin or tromethamine (if needed) in mildly acidified purified water (if stability permits) with or without benzalkonium chloride and polyvinyl alcohol. Amide prodrugs met with mixed success due to incomplete intraocular hydrolysis. Suspension and ocular inserts appear irritating to the inflamed eye. Oil drop may be a suitable option for insoluble drugs and ointment may be used for sustained effect. Recent studies showed that the use of colloidal nanoparticle formulations and the potent COX 2 inhibitor bromfenac may enhance NSAID efficacy in eye preparations.
\end{abstract}

KEY WORDS: anti-inflammatory; cyclodextrins; formulation; NSAID; ocular; PGE 2 .

\section{INTRODUCTION}

Inflammation is the manifestation of vascular and cellular response of the host tissue to injury. Injury to the tissue may be inflicted by physical or chemical agents, invasion of pathogens, ischemia, and excessive (hypersensitivity) or inappropriate (autoimmunity) operation of immune mechanisms. Inflammation facilitates the immune response and the subsequent removal of antigenic material and damaged tissue. As soon as the injury is recognized, the mechanisms to localize and clear foreign substances and damaged tissues are initiated. Further the response is amplified by activation of inflammatory cells and production of chemical mediators like acidic lipids e.g. prostaglandins (PGs), thromboxanes, leukotrienes; vasoactive amines, cytokines etc (1).

Acidic lipids are produced in the arachidonic cascade. Arachidonic acid is released from the phospholipid compo-

\footnotetext{
${ }^{1}$ Department of Pharmaceutical Sciences, Guru Jambheshwar University of Science \& Technology, Hisar, 125001 Haryana India.

${ }^{2}$ L.B.Rao Institute of Pharmaceutical Education and Research, Khambat, Anand, Gujarat 388620 India.

${ }^{3}$ Department of Pharmaceutics, Delhi Institute of Pharmaceutical Sciences and Research, Formerly College of Pharmacy, (University of Delhi), Pushp Vihar, Sector III, New Delhi 110017 India.

${ }^{4}$ To whom correspondence should be addressed. (e-mail: dkmajum daar@yahoo.com)
}

nent of the cell membrane by the action of phospholipase $A_{2}$. The arachidonic acid so produced enters either the cyclooxygenase or lipoxygenase pathway. Activation of cyclooxygenase pathway results in formation of PGs and thromboxanes, while the lipoxygenase pathway yields eicosanoids (hydroxyeicosatetraenoic acid and leukotrienes).

Ocular actions of PGs are manifested in three ways (2). Firstly, they act on intraocular pressure (IOP). PGE $_{1} \& \mathrm{E}_{2}$ increase the IOP by local vasodilation and increased permeability of blood aqueous barrier. On the other hand $P G F_{2 a}$ lowers the IOP which is attributed to increased uveoscleral outflow. Secondly they act on iris smooth muscle to cause miosis. Thirdly, PGs cause vasodilation and increase the vascular permeability resulting in increased aqueous humor protein concentration. Corticosteroids, the potent anti-inflammatory agents elicit their action by blocking the enzyme phospholipase $\mathrm{A}_{2}$ to inhibit arachidonic acid production, thereby preventing the synthesis of all the PGs, thromboxanes and eicosanoids. On the other hand non-steroidal anti-inflammatory drugs (NSAIDs) exert their anti-inflammatory action by inhibiting the enzymes cyclooxygenase (COX 1 \& COX 2).

The pharmacological approach of management of inflammation involves administration of anti-inflammatory agents. Topical administration of drugs is the most preferred route for management of ocular inflammations as it provides higher ocular drug concentrations, avoiding the systemic side effects associated with the oral administration. However due 
to the physiologic constraints of the eye only few of the antiinflammatory agents which possess certain physicochemical properties can be formulated into a suitable dosage form effective for the management of ocular inflammations. Corticosteroids used to be the mainstay of topical therapy in the management of ocular inflammations (3), but their antiinflammatory effect was outweighed by serious adverse effects like elevation of intraocular pressure, progression of cataracts, increased risk of infection and worsening of stromal melting (4). As a class, NSAIDs have proven to be a safe and effective alternative to corticosteroids in the topical management of ocular inflammations (5). Currently these drugs are used topically very widely in inhibition of intra-operative miosis, management of post-operative inflammation, treatment of seasonal allergic conjunctivitis, prevention and treatment of cystoid macular edema and in the control of pain after photo refractive keratectomy (6). NSAIDs have also been found to be useful in decreasing bacterial colonization of contact lenses and prevent bacterial adhesion to human corneal epithelial cells (7).

NSAIDs comprise of several chemically heterogeneous class of drugs which possess potent cyclooxygenase inhibitory activity. However, the topical use of NSAIDs in ophthalmology is limited to relatively water soluble salicylic acid, indole acetic acid, aryl acetic acid, aryl propionic acid and enolic acid derivatives (Table I). Most of the NSAIDs are weakly acidic drugs, which ionize at the $\mathrm{pH}$ of the lachrymal fluid and therefore have limited permeability through the anionic cornea which has an isoelectric point (pI) of 3.2 (8). Reducing the $\mathrm{pH}$ of the formulation increases the unionized fraction of the drug which enhances permeation. Being acidic, NSAIDs are inherently irritant (6) and reducing the $\mathrm{pH}$ of formulation further increases their irritation potential, as well as decreasing their aqueous solubility. In addition, the anionic nature of NSAIDs lends to the formation of insoluble complexes with cationic quaternary ammonium preservatives, such as benzalkonium chloride $(9,10)$. Thus; it has proved difficult to formulate topical NSAID formulations that are comfortable when applied topically to the eye. The present article gives an insight into various approaches used in topical ocular delivery of NSAIDs.

\section{SALICYLIC ACID DERIVATIVE}

\section{Aspirin}

Aspirin, 2-acetoxybenzoic acid, is slightly soluble in water and freely soluble in alcohol. Topically administered aspirin was found to significantly block arachidonic acid-induced lid closure and chemosis in rabbits (11) and inhibit the rise in secondary aqueous protein concentration as a result of paracentesis-induced blood aqueous barrier breakdown in dogs (12). In a comparative study on argon laser iris photocoagulation-induced miosis, rise in IOP and breakdown of blood aqueous barrier both topical aspirin $(1 \%, \mathrm{wt} / \mathrm{vol})$ and indomethacin $(1 \%, \mathrm{wt} / \mathrm{vol})$ were equally effective in inhibiting the rise in aqueous humor protein concentration and IOP, while only aspirin showed its inhibitory effect on pupillary response (13). In the treatment of pollen-induced allergic conjunctivitis topically administered aspirin (1\%, wt/vol) eye drops were found to be clinically efficacious and safe (14).
Aspirin has been reported to delay progression of cataracts by inhibiting aldose reductase (15). A topical formulation of aspirin lysine $(0.3 \%$, wt $/ \mathrm{vol})$ has been found to offer protection against galactosemic cataract in rats (16). The feasibility of transscleral, coulomb controlled iontophoretic mode for delivery of aspirin into vitreous chamber was investigated and compared with intravenous and topical routes (17). No clinical or histological tissue damage was observed following the topical or coulomb controlled iontophoretic modes of delivery. Further the results showed that higher concentrations of salicylic acid were achieved in all the tissues with coulomb controlled iontophoretic mode of delivery as compared to the topical and intravenous administration. The salicylic acid concentration in tissues of the posterior segment of eye was significantly lower with topical administration as compared to coulomb controlled iontophoretic or IV administration. The study concluded that coulomb controlled iontophoretic method of aspirin administration to the eye is safe and effective with avoidance of systemic side effects associated with IV administration.

\section{INDOLE ACETIC ACID DERIVATIVES}

\section{Indomethacin}

Indomethacin, [1-(4-chlorobenzoyl)-5-methylindol-3-yl] acetic acid, has been used topically as 0.5 or $1 \%$ (wt/vol) eye drops to prevent miosis during cataract surgery and to prevent cystoid macular edema (18). It is practically insoluble in water, and has been used in ophthalmology as aqueous solutions of sodium and tromethamine salt (19). Indomethacin is unstable in alkaline media and poorly soluble in acidic media, precipitating out of solution when the $\mathrm{pH}$ of the formulation is below 6.0. Indomethacin ophthalmic suspension buffered to pH 5.6 containing polyvinyl alcohol or hydroxypropyl methylcellulose (HPMC) as viscolizer was found to be physically and chemically stable (20). Attempt was made to prepare indomethacin $(0.1 \%$, wt $/ \mathrm{vol})$ aqueous formulation using Poloxamer-407 as solubilizer. The formulation was found to be stable, provided higher aqueous humor drug level and produced a faster resolution of symptoms of inflammation in immunogenic uveitis model as compared to the marketed formulation (21). Evaluation of a model aqueous ophthalmic formulation comprising indomethacin $(0.5 \%$, wt/vol), buffered to $\mathrm{pH}$ of 6.8 and solubilized using Pluronic F68, Pluronic F127 or polysorbate as solubilizer has been described (22). Pluronics solubilized formulations were observed to give chemically stable thermo-reversible gels, providing prolonged diffusion.

To overcome the poor ocular availability and local side effects of indomethacin, formulations based on oily suspension and oily emulsion have been evaluated. Aqueous humor penetration of indomethacin from oily suspension ( $1 \%$, wt/vol) was found to be significantly higher compared with an aqueous suspension (1\%, wt/vol) (23). For absorption, the drug will have to partition out of the oil into the aqueous phase. Prolonged residence of oily suspension in the conjunctival sac and favorable partition characteristics of the drug could account for the higher aqueous humor penetration of indomethacin from oily suspension compared with the aqueous suspension. Indomethacin, incorporated into 
$\mathrm{o} / \mathrm{w}$ emulsion of medium chain triglyceride(oil phase) stabilized by combination of phospholipids and an amphoteric surfactant, with $\mathrm{pH}$ of aqueous phase adjusted to 3.8 was evaluated for corneal permeation through excised rabbit cornea (24). The apparent corneal permeability of indometh- acin from the emulsion was found to be 3.8 fold higher than the conventional marketed aqueous formulation. The higher permeation of indomethacin from the emulsion was attributed to lower $\mathrm{pH}$ of the emulsion, providing a greater unionized lipophilic fraction of the drug. However, in vivo, the lower $\mathrm{pH}$

Table I. Physicochemical $(102,18)$ and Biopharmaceutical Characteristics of NSAIDs

\begin{tabular}{|c|c|c|c|c|c|c|}
\hline Drug & Structure & pKa & $\begin{array}{c}\text { Mol } \\
\text { wt }\end{array}$ & $\begin{array}{c}\text { Log } \\
\mathbf{P}\end{array}$ & $\begin{array}{c}\text { Relative } \\
\text { aqueous humor } \\
\text { bioavailability/conc }\end{array}$ & $\begin{array}{c}\text { Ref. } \\
\text { No }\end{array}$ \\
\hline
\end{tabular}

SALICYLIC ACID DERIVATIVE

Aspirin<smiles>CC(=O)Oc1ccccc1C(=O)O</smiles>

1.00 (Topical) $^{a}$

17

$3.5 \quad 180.2 \quad-1.1 \quad 0.28($ IV)

3.07 (Iontophoresis)

\section{INDOLE ACETIC ACID DERIVATIVES}<smiles>COc1ccc2c(c1)c(CC(=O)O)c(C)n2C(=O)c1ccc(Cl)cc1</smiles>

$\begin{array}{cccl} & & & 1 \text { (Aq. soln. })^{b} \\ 4.2 & 357.8 & 4.5 & 3 \text { (Nanoparticle) } \\ & & 3 \text { (Nanocapsule) } \\ & & 3 \text { (Nanoemulsion) } \\ & & & \\ & & & \\ & & & \\ & & & \\ & & & \\ & & --- & -\end{array}$

\section{ARYL ACETIC ACID DERIVATIVES}

Diclofenac<smiles>O=C(O)Cc1ccccc1Nc1c(Cl)cccc1Cl</smiles>

Ketorolac<smiles>O=C(c1ccccc1)c1ccc2n1CCC2C(=O)O</smiles>

Nepafenac<smiles>NC(=O)Cc1ccccc1C(=O)c1ccccc1N</smiles>

Bromfenac<smiles>Nc1c(CC(=O)O)cccc1C(=O)c1ccc(Br)cc1</smiles>

4.2

296.1<smiles>C1CCCC1</smiles>

1.0 (Aq. soln.) ${ }^{a}$

2.1 (Liposomes)

1.0 (Aqueous) $^{b}$
$376.4 \quad 2.32$.

3.16 (Soybean oil)

3.26 (Sesame oil) 
Table I (Continued)

\begin{tabular}{lccccccc}
\hline Drug & Structure & pKa & $\begin{array}{c}\text { Mol } \\
\text { wt }\end{array}$ & $\begin{array}{c}\text { Log } \\
\mathbf{P}\end{array}$ & $\begin{array}{c}\text { Relative } \\
\text { aqueous humor } \\
\text { bioavailability/conc }\end{array}$ & $\begin{array}{c}\text { Ref. } \\
\text { No }\end{array}$ \\
\hline Tolmetin & & & & 1.0 (Conventional) $^{b}$ & 66 \\
\end{tabular}

\section{ARYL PROPIONIC ACID DERIVATIVES}

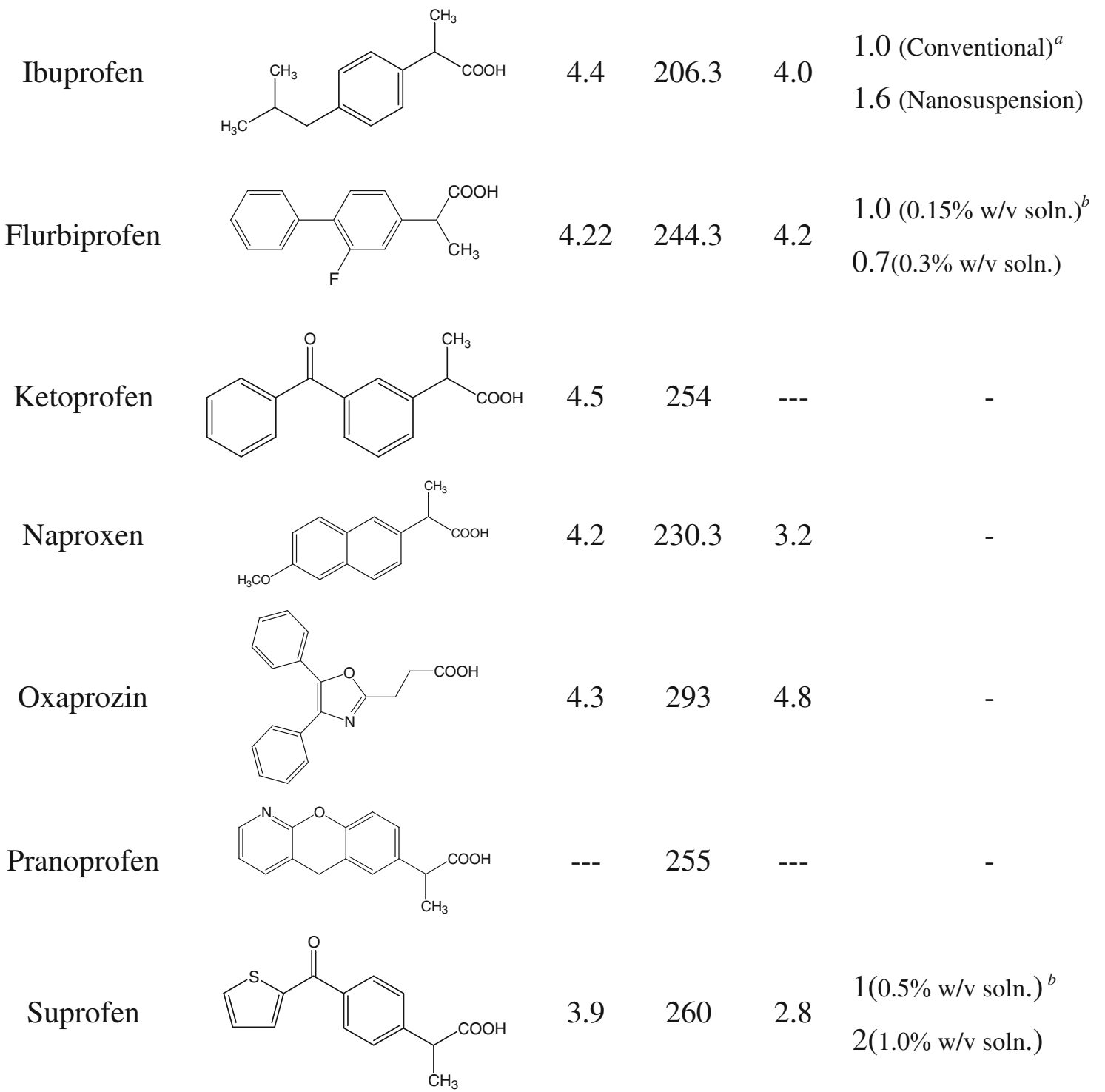

ENOLIC ACID DERIVATIVE

Piroxicam<smiles>CN1C(C(=O)Nc2ccccn2)=C(O)c2ccccc2S1(=O)=O</smiles>

$\begin{array}{lll}6.3 & 331.3 \quad 3.1\end{array}$ 
of the aqueous phase $(\mathrm{pH}=3.8)$ would depress the $\mathrm{pH}$ of lachrymal fluid upon instillation to the eye. This will result in $\mathrm{pH}$-induced lachrymation and loss of drug from the conjunctival sac resulting in reduced bioavailability. Return of the $\mathrm{pH}$ of lachrymal fluid back to physiological range will reduce ocular penetration of drug due to ionization. Thus the lower $\mathrm{pH}$ of the emulsion may not offer a net benefit in absorption in vivo.

Polyepsilon caprolactone based nanoparticle, nanocapsule and nanoemulsion formulations of indomethacin, of mean size $225 \mathrm{~nm}$, prepared by interfacial deposition, nanoprecipitation and spontaneous emulsification have been reported (25). In vitro comparison of colloidal carriers with commercial eye drops revealed a threefold higher corneal penetration of indomethacin from colloidal systems. Further, in vivo evaluation of these colloidal systems in rabbit eye, showed a threefold higher drug concentration in aqueous humor at $0.5 \mathrm{~h}$ post instillation and a $300 \%$ increase in ocular availability of indomethacin compared with a commercial solution dosage form while a polymer entrapped microparticle formulation $(6.5 \mu$ size $)$ did not increase the ocular availability (26). The colloidal carriers penetrated the corneal epithelium by endocytosis without damaging the membrane. Colloidal nature of the carriers have been suggested to be responsible for increased ocular availability of indomethacin. The ocular pharmacokinetics data of nanoformulations suggest aqueous humor $t_{1 / 2}$ of indomethacin $(65-74 \mathrm{~min})$ does not increase on instillation of colloidal formulations indicating inability of the dosage forms to have a prolonged effect.

To prolong the precorneal residence and thus enhance the ocular availability of topically applied indomethacin drops, an ion-activated in situ gelling system based on gellan gum was formulated. The formulation sustained the in vitro release for $8 \mathrm{~h}$ and was found to be therapeutically effective in uveitis induced rabbit eye model (27).

Ocular inserts (28) and scleral implants $(29,30)$ have been employed to extend the release rate of indomethacin. Ocular inserts of indomethacin were fabricated using a combination of low and high molecular weight polyvinyl alcohol. The ex-vivo permeation of drug from ocular inserts was evaluated through excised goat cornea, and it was observed that physical cross linking of inserts by freeze-thaw cycling and increase in the proportion of low molecular weight polyvinyl alcohol decreased the apparent corneal permeability of indomethacin (28).

Film type scleral implants of indomethacin based on sodium alginate (29) and gellan gum (30) have also been formulated. The in vitro release of indomethacin from scleral implants depended upon the concentration of plasticizer. Surface cross-linking of the implants by calcium chloride retarded the in vitro release. In vivo evaluation of scleral implants in uveitis induced rabbit eye model showed a marked improvement in the clinical parameters of inflammation in the implanted eye as compared to the control eye. The scleral implants of gellan gum and sodium alginate survived in vivo up to 3 and 2 weeks respectively.

\section{Bendazac}

Bendazac, (1-benzyl-1H-indazol-3-yl-oxy)-acetic acid, is structurally related to indomethacin. Its lysine salt has been reported to be absorbed better than the parent compound. It is applied topically as bendazac lysine $0.5 \%$ (wt/vol) aqueous solution for delaying the progression of cataract (31). Topical application of bendazac is associated with transient burning sensation.

\section{ARYL ACETIC ACID DERIVATIVES}

\section{Diclofenac}

Diclofenac, 2(2, 6-dichloroanilino) phenyl acetic acid, has a poor aqueous solubility. It is usually used as sodium, potassium and diethylamine salts (32). For ophthalmic use diclofenac is commercially available as $0.1 \%$ (wt/vol) aqueous solution of its sodium salt. Diclofenac is applied topically in the eye for the management of pain in corneal epithelial defects following surgery or accidental trauma, treatment of postoperative ocular inflammations, chronic non-infectious inflammations, and prevention of intra-operative miosis during cataract surgery and for symptomatic relief of seasonal allergic conjunctivitis (18). At the physiological $\mathrm{pH}$ of eye it primarily exists in ionized form and thus has limited permeability. A significantly higher corneal permeation of diclofenac was observed from solutions buffered to a lower $\mathrm{pH}$ (6.0) (10). Since reducing the $\mathrm{pH}$ also leads to precipitation, a number of approaches like use of solubilizer like polyoxyethylene-35-castor oil, and hydroxypropyl- $\beta$-cyclodextrin (33) have been employed. In one study n-octenylsuccinate starch has been suggested as an alternative solubilizer for diclofenac, and was found to give better permeation across excised porcine cornea than the polyoxyethylene35-castor oil solubilized diclofenac sodium solutions (34). Acidified solutions ( $\mathrm{pH}$ 6.5) of diclofenac complexed with cyclodextrins to increase the solubility were reported to permeate better through porcine cornea than the neutral ( $\mathrm{pH}$ 7.0) diclofenac solutions (33). In a patent claim, stable and non-irritating formulations of NSAIDs e.g. diclofenac, have been prepared using $\alpha$-tocopheryl polyethylene glycol succinate as solubilizer and preserved using benzalkonium chloride (35). Topical use of diclofenac was reported to cause severe corneal toxicity including corneal melting (36). This adverse event was investigated and it was traced to be due to a possible role of $\alpha$-tocopheryl polyethylene glycol succinate solubilizer in causing aberrant expression of matrix metalloproteinase enzymes (37). Adjustment of tonicity of aqueous diclofenac ophthalmic solutions with mannitol was found to significantly reduce the corneal permeation of diclofenac. Using a combination of methylparaben and propylparaben as preservatives has been found to be favorable for corneal permeation. On the other hand employment of any one of the preservatives likes sorbic acid, benzyl alcohol, thiomersal and phenylmercuric acetate has been found to adversely affect the in vitro corneal permeation of diclofenac (10). Benzalkonium chloride at $0.01 \%(\mathrm{wt} / \mathrm{vol})$ concentration is incompatible with diclofenac $0.1 \%$ (wt/vol) solution (10). However, several marketed diclofenac ophthalmic solutions containing benzalkonium chloride $(0.02 \%$, wt/vol) were clear and the formulations showed enhanced permeation of drug through excised cornea. Surface tension measurement of the formulations indicated presence of additional surfactant besides benzalkonium chloride which could account for the increased permeation. In an attempt to overcome the poor aqueous solubility 
of diclofenac and shorter residence time of aqueous drop in the conjunctival sac, its oily solution has been formulated. The oil drop of diclofenac free acid $(0.2 \% \mathrm{wt} / \mathrm{vol})$ in sesame oil provided more extensive apparent in vitro corneal permeability of diclofenac compared with diclofenac solutions formulated in arachis, castor, safflower, mustard, soybean, and sunflower oils. Addition of benzyl alcohol to oil drop increased permeation further. Partition experiments with oil drop and phosphate buffer $(\mathrm{pH}$ 7.4) indicated increased partitioning of diclofenac in aqueous phase in presence of benzyl alcohol. Since only the drug present in aqueous phase could be absorbed, increased partitioning in aqueous phase increases corneal permeability from the formulation containing benzyl alcohol (38).

Apart from the commercially available conventional dosage form, various other delivery systems like novel polydisperse carrier solution (Sophisen) (39), ophthalmic gels (40), ocular inserts $(41,42)$ and liposomes (43) of diclofenac have been evaluated. Polydisperse carrier solutions of diclofenac were reported to provide better tolerance and sustained release of diclofenac (39). Diclofenac sodium $(0.1 \%$, wt/vol) ophthalmic gels were formulated using sodium carboxymethyl cellulose $(1 \%$, wt/vol), hydroxypropyl methylcellulose (HPMC) $(4 \%, \mathrm{wt} / \mathrm{vol})$ or methylcellulose $(3 \%, \mathrm{wt} / \mathrm{vol})$. The gel formulated using HPMC provided better ocular tolerance and sustained in vitro drug release up to $9 \mathrm{~h}$ (40). Using a combination of methylcellulose and sodium carboxymethyl cellulose, ocular insert of diclofenac was also prepared and was found to be stable and sustain the release of diclofenac for $12 \mathrm{~h}$ (41). In yet another study to improve the intraocular retention of inserts, mucoadhesive thiolated ocular inserts comprising of polyacrylic acid-cysteine conjugate as polymeric matrix, containing either diclofenac sodium or diclofenac-tris (hydroxymethyl)-amino methane were prepared and evaluated (42). In vitro release studies conducted using simulated lachrymal fluid revealed a significantly lesser release of drug from diclofenac-tris inserts compared with diclofenac sodium inserts. The inserts were successful in providing a controlled drug release with release rate approximating zero order release kinetics. Pre-corneal retention of diclofenac sodium has also been reported to be increased by use of liposomes. The cationic liposomes of diclofenac sodium prepared by reversephase evaporation were observed to provide a $211 \%$ increase in aqueous humor concentration of drug compared with conventional aqueous eye drop formulation (43).

\section{Ketorolac}

Ketorolac, 5-benzoyl-2,3-dihydro-1H-pyrrolizine-1-carboxylic acid, is a racemic mixture. The anti-inflammatory activity of the levorotatory $(l)$ isomer of the drug is twice that of dextrorotatory isomer $(d)(44)$. It is commercially available as the tromethamine salt which has higher aqueous solubility compared to ketorolac. Ketorolac is applied topically in the management of seasonal allergic conjunctivitis, postoperative ocular pain and inflammation (18). Instillation of ketorolac tromethamine $(0.5 \%, \mathrm{wt} / \mathrm{vol})$ aqueous solution was associated with ocular irritation, mainly burning and stinging. To reduce the incidence of this adverse affect, use of lower concentration of ketorolac tromethamine $(0.4 \%$, wt $/ \mathrm{vol})$ has been advocated (45).
Investigations on the in vitro corneal permeation of ketorolac revealed that reducing the $\mathrm{pH}$ of formulation increased the corneal penetration of ketorolac, with ketorolac tromethamine aqueous drop $(0.5 \% \mathrm{wt} / \mathrm{vol})$ formulated in phosphate buffer ( $\mathrm{pH} 4.5$ ) providing more extensive in vitro corneal permeation (46). Ketorolac is chemically unstable, undergoing acid and base catalyzed autooxidation (47). It was observed that unbuffered ketorolac tromethamine drops of pH 6.5 to 8.5 provided enhanced chemical stability. Keeping the stability and corneal permeation of ketorolac in view, unbuffered ketorolac tromethamine ophthalmic solution ( $\mathrm{pH}$ 6.5) was considered optimal (46). Preservation of the ketorolac aqueous drops with benzalkonium chloride, EDTA, chlorbutanol, phenylmercuric acetate and phenylmercuric nitrate was associated with increased corneal permeation (48). On the other hand preservation with thiomersal was found to decrease the corneal permeation of ketorolac. Presence of ascorbic acid, sodium sulphite or citric acid in ketorolac tromethamine ophthalmic solution had a negative impact on the corneal permeation of ketorolac, while sodium metabisulphite favored corneal permeation. Among all the formulations ketorolac tromethamine ophthalmic solution $(0.5 \% \mathrm{wt} / \mathrm{vol})$ containing benzalkonium chloride $(0.01 \% \mathrm{wt} / \mathrm{vol})$ and EDTA $(0.01 \% \mathrm{wt} / \mathrm{vol})$ provided more extensive permeation.

Apart from the aqueous solutions, oily solution and ophthalmic ointment preparations of ketorolac have also been formulated (49). The results show that oil drop of ketorolac free acid formulated in sesame oil and preserved with benzyl alcohol provided more extensive in vitro corneal permeation of ketorolac. Partition experiments between oil and phosphate buffer ( $\mathrm{pH}$ 7.4) showed increased partition of ketorolac into the aqueous phase from sesame oil drop which could account for the increased permeation. Both ketorolac free acid and ketorolac tromethamine were formulated as ointment dosage forms. Formulation containing ketorolac tromethamine aqueous solution dispersed in ointment base showed higher in vitro corneal permeation compared to formulations containing solid ketorolac tromethamine and ketorolac free acid dispersed in ointment base. Chemical form and physical state of the drug, thus, could affect ocular permeation. In vivo comparison of the aqueous, oil and ointment formulations of ketorolac for ocular availability in rabbits revealed that the ketorolac drops $(0.2 \%$, wt/vol $)$ formulated in sesame oil and soybean oil provided higher ocular availability followed by ointment and aqueous formulations (50). The ointment formulation provided prolonged precorneal residence and sustained effect. Aqueous humor $t_{1 / 2}$ of ketorolac was $10 \mathrm{~h}$ with ointment and $6.6 \mathrm{~h}$ with oil drops. However, the permeation enhancing effect of benzalkonium chloride and EDTA combination, observed in the in vitro studies, did not translate into increased ocular availability during in vivo assessment. The rate of ocular absorption was increased but not the extent. This may be attributed to the increased lachrymation induced by ocular irritant (51) effects of benzalkonium chloride and EDTA.

Pharmacodynamic evaluation of aqueous, oily and ointment formulations of ketorolac in $\mathrm{PGE}_{2}$-induced ocular inflammation in rabbits established the efficacy of ketorolac formulations in inhibiting $\mathrm{PGE}_{2}$-induced ocular inflammation. Prolonged topical use of the formulations did not produce any gastrointestinal ulceration in rats, a common side effect 
associated with NSAIDs due to PG inhibition, which suggests safety of the products on chronic administration (52).

In another study reservoir type ocular inserts of ketorolac were formulated using HPMC or methylcellulose and povidone as polymeric films, and ethylcellulose film as rate controlling membrane (53). The ocular inserts casted using HPMC (4\%) and ethyl cellulose (3\%) were found to sustain ketorolac tromethamine release by zero order kinetics for $22 \mathrm{~h}$.

To increase the ocular availability, ketorolac was entrapped in $\mathrm{N}$-isopropylacrylamide, vinyl pyrrolidone and acrylic acid based copolymeric nanoparticles. The particles were spherical and had a size of $35 \mathrm{~nm}$. In vitro permeation studies through excised cornea revealed twofold higher permeation of drug from nanoparticle formulation, compared with an aqueous suspension of the drug. Pharmacodynamic evaluation of nanoparticle formulation in $\mathrm{PGE}_{2}$.induced ocular inflammation in rabbits showed a significantly higher ocular anti-inflammatory activity for $5 \mathrm{~h}$ compared with the aqueous suspension (54), which has been attributed to the small size of the particles and mucoadhesiveness. The nanoparticle formulation did not show any corneal damage during in vitro study.

\section{Nepafenac}

Nepafenac, 2-amino-3-benzoylbenzeneacetamide,is a prodrug (55) which rapidly penetrates the cornea. In vitro permeation studies across the human cornea showed six times faster penetration of nepafenac than diclofenac. After penetrating the cornea nepafenac is deaminated by intraocular hydrolases to amfenac [(2-amino-3-benzoyl phenyl) acetate], a potent inhibitor of COX-1 and COX-2 (56). Investigations with concanavalin-A-induced retinal inflammation in rabbits revealed a greater degree of inhibition of inflammation with nepafenac as compared to ketorolac and diclofenac (57). A recent study compared the $\mathrm{PGE}_{2}$-inhibition and aqueous humor penetration of ketorolac and nepafenac in patients undergoing phacoemulsification. The patients received ketorolac $(0.4 \% \mathrm{wt} / \mathrm{vol})$ solution or nepafenac $(0.1 \% \mathrm{wt} / \mathrm{vol})$ suspension four times daily for 2 days before cataract extraction. Ketorolac showed a significantly greater inhibition of $\mathrm{PGE}_{2}$ and a higher aqueous humor penetration than the nepafenac at surgery, which contradicts an earlier finding (58). The decreased inhibition of $\mathrm{PGE}_{2}$ by nepafenac, was attributed to the presence of considerable amount of unhydrolysed nepafenac (prodrug) in the aqueous humor of patients suggesting inadequate metabolism to amfenac to prevent inflammation. Thus, it was concluded that the prodrug character of nepafenac does not confer any advantage with regard to ocular penetration and $\mathrm{PGE}_{2}$ inhibition. In another study where patients received nepafenac $0.1 \%$ (wt/vol) ophthalmic suspension one day before cataract surgery to 14th day after surgery, nepafenac was found to be effective in preventing and treating ocular inflammation and pain associated with cataract surgery (59). During prolonged treatment the metabolism of nepafenac appears to be sufficient to produce amfenac for treating inflammation and pain.

\section{Bromfenac}

Bromfenac,2-amino-3-(4-bromobenzoyl) benzene acetic acid, is structurally identical to amfenac with the exception of a bromine atom at the $\mathrm{C}_{4}$ position. Introduction of bromine in bromfenac makes it more lipophilic, facilitating corneal penetration, increased duration of action and enhanced COX-2 inhibitory activity $(60,61)$. It is available as sesquihydrate sodium salt. Aqueous drops of sodium salt (containing equivalent of $0.09 \% \mathrm{wt} / \mathrm{vol}$ bromfenac) have been used in the management of postoperative ocular inflammation and pain in patients who have undergone cataract extraction (62). Commercially available formulation is buffered to $\mathrm{pH}$ of 8.3 and contains polysorbate 80 as solubilizer and benzalkonium chloride $(0.005 \%)$ as preservative. It has a good ocular penetration and significant amounts are also absorbed systemically on topical administration. Bromfenac has been found to be 3.7, 6.5 and 18 times more potent inhibitor of COX-2 than diclofenac, amfenac (63) and ketorolac (64) respectively. In another study involving arachidonic acid- and carrageenaninduced conjunctival edema in rabbits, bromfenac was found to be 3.8 and 10.9 times more potent than indomethacin and pranoprofen as inhibitor of PG production (65).

\section{Tolmetin}

Tolmetin, 1-methyl-5-(4-methylbenzoyl)-1H-pyrrole-2acetic acid, is usually used as sodium salt which is freely soluble in water and slightly soluble in alcohol. Ocular antiinflammatory activity of aqueous tolmetin $(0.5 \%)$ ophthalmic solution was evaluated and compared with a mucoadhesive formulation of tolmetin in sodium arachidonate-induced ocular inflammation in rabbits (66). Tolmetin treatment was found to significantly reduce the signs and symptoms of ocular inflammation. A significant reduction in sodium arachidonate-induced aqueous humor $\mathrm{PGE}_{2}$ levels, polymorphonuclear leukocytes, protein concentration and IOP rise was observed in tolmetin treated eyes. The results of the pharmacokinetic evaluation revealed significantly higher aqueous humor drug concentrations in inflamed eyes as compared to uninflamed eyes. Further, the mucoadhesive formulation of tolmetin provided 2.6- and 2.0-fold higher aqueous humor area under the concentration-time curve (AUC) values compared to the aqueous formulation in uninflamed and inflamed eyes respectively.

\section{ARYL PROPIONIC ACID DERIVATIVES}

\section{Ibuprofen}

Ibuprofen, 2-(4-isobutylphenyl) propionic acid, is practically insoluble in water and to overcome its poor aqueous solubility sodium and lysine salts have been employed (67). In an in vitro study it was observed that increase in ibuprofen concentration in aqueous drops reduced the \% permeation or in vitro ocular availability. Increase in concentration of drug in the corneal epithelial side does not result in proportionate increase in the amount permeated because only the quantity of drug needed to saturate corneal epithelium could permeate through stroma and endothelium. As a result increase in concentration decreases in vitro ocular availability. Permeation of ibuprofen was higher at $\mathrm{pH} 6.4$ and decreased on increase of $\mathrm{pH}$ to physiological range. Benzalkonium chloride and chlorbutanol increased permeation of ibuprofen. Benzalkonium chloride $(0.01 \%$ wt/vol) when mixed with 
$0.5 \%$ (wt/vol) ibuprofen ( $\mathrm{pH}$ 6.4) develops opalescence indicating formation of less water soluble ion pair due to cation-anion interaction. Increased permeation of ibuprofen in the presence of benzalkonium chloride appears to be due to formation of a more lipid-soluble ion pair (9). In another study, 2(4-hydroxyethoxy phenyl) acetic acid and 2(4-hydroxyethoxy phenyl) propionic acid, the more water soluble structural analogs of ibufenac and ibuprofen demonstrated 3.3-fold lesser apparent corneal permeability coefficient than their parent compounds in rabbit eye (68). In vivo evaluation of ocular anti-inflammatory activity of ibufenac and ibuprofen structural analogs against clove oil or arachidonic acidinduced inflammation showed the anti-inflammatory activity to decrease in the order of ibufenac $>$ ibuprofen $>2(4-$ hydroxyethoxy phenyl) acetic acid > 2(4-hydroxyethoxy phenyl) propionic acid. The hydroxyethoxy analogs had a 60 -fold greater aqueous solubility and 1/1500 fold less lipid solubility compared to ibufenac and ibuprofen. Considering the lipophilicity of the three layers of the cornea: epithelium (lipophilic), stroma (hydrophilic) and endothelium (less lipophilic than epithelium), it can be reasoned that a drug that possesses high lipid solubility but poor aqueous solubility will not be able to penetrate beyond corneal epithelium while a highly water soluble drug having limited lipid solubility will not be able to penetrate corneal epithelium unless assisted by a carrier. Hence for corneal penetration, a drug must have a balanced solubility in both water and lipid. The reduced corneal permeability/anti-inflammatory activity of the hydroxyethoxy analogs of ibufenac and ibuprofen appears to be due to reduced lipid solubility. Topical application of ibuprofen and ibufenac was associated with local irritation and ocular discomfort, which was attributed to the higher surface activity of the compounds.

In a recent study, ibuprofen amino acid compounds were evaluated for their emulsifying and cytotoxic properties. It was observed that different ibuprofen salts possess surface activity in the order of ibuprofen lysinate $>$ ibuprofen sodium $>$ ibuprofen arginate $>$ ibuprofen histidinate (69). The hemolytic behavior of ibuprofen salts correlated with their surface activity. Histological examination of excised porcine corneas treated with solutions of ibuprofen salts revealed ibuprofen histidinate as least cytotoxic, while lysinate and arginate salts were found to adversely affect the corneal integrity. Cationic amino acid salts of drug thus appear to be detrimental to the anionic cornea and caution is needed while using lysine salt which is most commonly used for topical delivery. However, treatment of excised porcine corneas with emulsions of ibuprofen lysinate and arginate did not affect the corneal integrity.

In order to improve ocular availability, ibuprofen loaded polymeric nanoparticle suspensions were made from Eudragit RS 100 by a quasi emulsion solvent diffusion technique. The nanosuspension inhibited the miotic response to ocular trauma (paracentesis) in rabbits comparable to a control aqueous formulation. The nanosuspension showed a mean size of $100 \mathrm{~nm}$ and a positive charge which helps in corneal adhesion. A gradual and prolonged release of the drug associated with increased retention on the corneal surface resulted in a higher aqueous humor drug level compared with an aqueous solution. The nanosuspension did not show any ocular tissue toxicity (70).

\section{Flurbiprofen}

Flurbiprofen, 2-(2-fluorobiphenyl-4-yl) propionic acid, is practically insoluble in water. Aqueous solutions of flurbiprofen sodium $(0.03 \% \mathrm{wt} / \mathrm{vol})$ are employed to inhibit intraoperative miosis during cataract surgery and to control postoperative inflammation of the anterior segment of the eye (18). Flurbiprofen sodium eye drops have also been used in the topical treatment of cystoid macular edema. Flurbiprofen ophthalmic solution USP has a recommended $\mathrm{pH}$ of 6-7. The S-(+) isomer of flurbiprofen has been found to be 100 times more potent inhibitor of prostaglandin synthesis than the R-(-) isomer (71). In one of the studies, preservative-free aqueous eye drops of $\mathrm{RS}( \pm)$-flurbiprofen $(0.03 \%$, wt/vol $), \mathrm{S}$ (+)-flurbiprofen $(0.015 \%$, wt/vol) and $\mathrm{R}(-)$-flurbiprofen $(0.015 \%, w t / v o l)$ were formulated using phosphate buffer (0.13 M, pH 7.4) as the vehicle and packaged in glass containers (72). The formulations were found to have a shelf life of 4 years, and in vitro enantiomeric inversion was not detected. The S (+)-flurbiprofen $(0.015 \%$, wt/vol) drops were found to produce inhibition of PG synthesis comparable to RS ( \pm )-flurbiprofen $(0.03 \%$, wt/vol) eye drops. Studies on in vitro corneal permeation of flurbiprofen have revealed that increase in the concentration of drug in aqueous drops decreased the \% permeation or in vitro ocular availability. Permeation of flurbiprofen was higher at $\mathrm{pH} 6.4$ and decreased on increase of $\mathrm{pH}$ to physiological range. Permeation of flurbiprofen was enhanced by benzalkonium chloride due to formation of more lipid soluble ion-pair between anionic flurbiprofen and cationic benzalkonium chloride which develops opalescence. Phenylmercuric nitrate also enhanced corneal permeation of flurbiprofen (9). An in vivo study, which reported $30 \%$ greater ocular availability of flurbiprofen from flurbiprofen $(0.15 \%$, wt/vol) topical aqueous drop compared with flurbiprofen $(0.30 \%$, wt/vol) topical solution, supports the in vitro data on the effect of drug concentration on corneal permeation (73). Flurbiprofen solutions of concentration greater than $0.2 \%$ (wt/vol) are quite irritating. A topical aqueous flurbiprofen ophthalmic formulation comprising of $\gamma$ - or $\beta$-cyclodextrin to achieve higher solubility of flurbiprofen has been disclosed in a patent claim (74). The formulation was found to be non-irritating even in the presence of higher concentrations of flurbiprofen. As compared to the conventional flurbiprofen solution, formulations containing cyclodextrin provided a greater inhibition of increase in blood-aqueous barrier permeability after cataract operations. Reducing the $\mathrm{pH}$ of cyclodextrin containing flurbiprofen formulation from 8.0 to 5.3 provided a 2.7 fold increase in intraocular permeation of flurbiprofen in rabbit's aqueous humor, whereas in case of conventional formulation, 2.2 fold increases were observed. The improvement in intraocular permeability of cyclodextrin-containing formulation at lower $\mathrm{pH}$ was attributed to its much lesser irritation potential. Further the results reveal a 1.5 fold greater intraocular permeation of flurbiprofen from formulations containing viscolizers (HPMC or hydroxy ethyl cellulose, $0.2 \%$, wt $/ \mathrm{vol}$ ) as compared to formulation without viscolizers.

A patent claim (75) describes the amide derivatives of amfenac, bromfenac, diclofenac, ketorolac, flurbiprofen and suprofen for treatment of ocular inflammation. In vitro 
corneal permeation across excised rabbit cornea revealed higher apparent permeability coefficient for amide derivatives of amfenac and diclofenac compared to the rest. However the amide derivatives of bromfenac, diclofenac and suprofen were resistant to hydrolytic bioactivation in the iris-ciliary body. The amide derivatives of amfenac and flurbiprofen significantly inhibited paracentesis-induced blood aqueous barrier breakdown (75).

In an attempt to improve the ocular availability, flurbiprofen-loaded cationic polymeric nanoparticle suspensions, of mean size $100 \mathrm{~nm}$, were prepared from Eudragit RS 100 and RL 100 using quasi emulsion solvent diffusion technique. In vitro dissolution tests showed a controlled release profile of flurbiprofen from the nanoparticles. In vivo investigation of the flurbiprofen loaded RS nanosuspension in paracentesisinduced miosis in rabbits indicated an efficacy comparable to control eye drop formulation. The nanosuspension also provided higher aqueous humor drug level. The formulation did not show any sign of toxicity or irritation to ocular tissue (76).

Biodegradable flurbiprofen nanoparticles based on poly (lactic/glycolic) acid have also been prepared using solvent displacement technique. The nanosuspensions were found to possess excellent ocular tolerance. Further the prepared flurbiprofen nanosuspension was found to afford significant protection against sodium arachidonate-induced inflammation in rabbit eyes (77).

\section{Ketoprofen}

Ketoprofen, 3-benzoyl- $\alpha$-methylbenzeneacetic acid, is a racemic mixture. The $\mathrm{S}(+)$ enantiomer of ketoprofen has twice the activity of the racemic mixture. The ocular antiinflammatory activity of topical ketoprofen $(0.01 \%$, wt/vol) was evaluated in rabbit corneal epithelial wound model (78). Topical ketoprofen was observed to inhibit PG synthesis in conjunctiva and iris-ciliary body, and to prevent the release of polymorphonuclear leukocytes into the tear fluid of rabbits. Further it did not interfere with wound healing after complete corneal de-epithelialization in rabbits.

\section{Naproxen}

Naproxen, (+)-2-(6-methoxy-2-naphthyl) propionic acid, is practically insoluble in water. A study reports the use of oxyethylated methyl esters of rape oil fatty acids (Rofams) as solubilizer in naproxen eye drops (79). Topical administration of aqueous naproxen sodium eye drops was found to provide a significant protection against sodium arachidonate-induced rise in aqueous humor $\mathrm{PGE}_{2}$, protein and polymorphonuclear leukocytes (80). Naproxen was also found to afford protection in rabbits against inflammatory response induced by anterior chamber paracentesis (81). In a comparative study, naproxen sodium $(0.2 \%$, wt/vol $)$ drops were found to be as effective as diclofenac sodium $(0.1 \%$, wt/vol) drops in controlling post operative inflammation after uncomplicated cataract surgery (82). Naproxen $(0.1 \%$, wt/vol and $0.2 \%$, wt/vol) eye drops were explored for controlling ocular inflammation in patients having phacoemulsification and intra ocular lens implantation (83). Naproxen eye drops were found to be safer and tolerable. Further, naproxen $(0.2 \%$, wt/vol) drops were reported to be more efficacious than the naproxen $(0.1 \%$, wt/vol $)$ drops in controlling the signs and symptoms of ocular inflammation.

\section{Oxaprozin}

Oxaprozin, 3-(4, 5-diphenyloxazol-2-yl)-propionic acid, is slightly soluble in alcohol and insoluble in water. Oxaprozin $(0.1 \%, w t / v o l)$ aqueous eye drops significantly protected rabbits against arachidonate-induced conjunctival inflammation and iris hyperemia (84), and arachidonate-induced rise in protein and polymorphonuclear leukocytes concentration in the aqueous humor. Pharmacokinetic evaluation for aqueous humor bioavailability of oxaprozin revealed that peak aqueous drug levels were achieved $60 \mathrm{~min}$ post-instillation. Further a 4-fold higher aqueous humor bioavailability was observed in inflamed eyes as compared to control eyes. In another study diethylene glycol monoethyl ether (Transcutol P) was evaluated as permeation enhancer $(0.005-0.03 \%)$ for oxaprozin using isolated rabbit cornea (85), and it was found to increase the lag time and decrease the apparent corneal permeability of oxaprozin, with maximum decrease of 2.8fold at a concentration of $0.03 \%$. The decreased corneal permeability of lipophilic oxaprozin was attributed to corneal hydration barrier.

\section{Pranoprofen}

Pranoprofen, $\alpha$-methyl-5H-[1]-benzopyrano [2,3-b]-pyridine-7-acetic acid, is applied topically as $0.1 \%$ (wt/vol) aqueous solution in the management of ocular inflammations. Topically applied pranoprofen has been demonstrated to possess analgesic and ocular anti-inflammatory activity comparable to flurbiprofen in endotoxin-induced uveitis model (86). It has also been found to be as effective as diclofenac sodium $(0.1 \%$, wt/vol $)$ in reducing pain and inflammation after strabismus surgery (87).

Pre-treatment with mydriatic eye drops comprising of tropicamide $(0.5 \%, \mathrm{wt} / \mathrm{vol})$ and phenylephrine $(0.5 \%, \mathrm{wt} / \mathrm{vol})$ was found to provide 2- to 3-fold higher intraocular concentration of pranoprofen (88). Investigation on the mechanism of mydriatic-induced increased permeation of pranoprofen showed phenylephrine to be responsible for increased corneal permeation. Further it was observed that mixing phenylephrine with pranoprofen increased octanol/buffer partition coefficient of both pranoprofen and phenylephrine. The increased permeation of pranoprofen in presence of phenylephrine was attributed to formation of more lipophilic ion-pair between anionic pranoprofen and cationic phenylephrine.

Pranoprofen is inherently irritating to the eye. It was observed that adjustment of isotonicity by boric acid provides the formulation with least irritation potential as compared to tonicity adjustment with sodium chloride, mannitol or glycerine (89). Pranoprofen is chemically unstable as it undergoes photochemical oxidation in aqueous solution. A stable aqueous formulation of pranoprofen utilizing butylated hydroxyanisole/butylated hydroxytoluene/methionine/tryptophan as antioxidants has been described in a patent claim (90). Pranoprofen is incompatible with benzalkonium chlo- 
ride forming turbid solutions. To overcome this incompatibility polysorbate 80 has been utilized as the solubilizer (91). It was found that the incompatibility between benzalkonium chloride and pranoprofen can be avoided by adding benzalkonium chloride to pranoprofen in the presence of tromethamine. Further addition of tromethamine to pranoprofen solution reduced the ocular irritation of pranoprofen.

\section{Suprofen}

Suprofen, $\alpha$-methyl-4-(2-thienylcarbonyl) benzene acetic acid, is sparingly soluble in water. Suprofen ophthalmic solution USP consists of suprofen dissolved in a buffered isotonic vehicle having a $\mathrm{pH}$ of $6.5-8.5$. Suprofen $1 \%(\mathrm{wt} / \mathrm{vol})$ eye drops are applied topically to inhibit the intra operative miosis during ocular surgery (18). Suprofen eye drops have been found to be useful in treatment of contact lensassociated giant papillary conjunctivitis (92). Suprofen does not interfere with the stromal wound healing (93). Suprofen eye drops may cause local reactions including discomfort, itching, pain and photophobia. In an ocular bioavailability study in rabbits, suprofen $1.0 \%$ (wt/vol) drop provided a 2fold higher ocular bioavailability of suprofen compared with eye drop of $0.5 \%$ (wt/vol) concentration (94). However there was no significant difference in corneal anti-inflammatory effect of suprofen between these concentrations against clove oil-induced corneal inflammation. In a comparative study involving suprofen, tolmetin, flurbiprofen and diclofenac in treatment of experimental blood aqueous barrier disruption in dogs, suprofen was found to be more efficacious than tolmetin but less efficacious than diclofenac and flurbiprofen (95).

Suprofen is a racemic mixture with $70 \%$ of its activity due to its (+)-enantiomer (96). An ophthalmic formulation of half strength $(+)$-suprofen is devoid of acute stinging sensation associated with full strength $( \pm)$-suprofen. Further, the use of pentanediol ester and butylamine amide derivatives of (+)-suprofen free from corresponding (-)-suprofen species as ophthalmic anti-inflammatory agents have been reported (96). These derivatives have been claimed to provide improved ocular bioavailability of suprofen. However in vivo data regarding the intraocular hydrolysis of the derivatives or their anti-inflammatory activity were not provided (96).

\section{ENOLIC ACID DERIVATIVE}

\section{Piroxicam}

Piroxicam, 4-hydroxy-2-methyl-N-(2-pyridyl)-2H-1,2benzothiazine-3-carboxamide-1, 1-dioxide, is practically insoluble in water and dilute acids, slightly soluble in alcohol and in aqueous alkaline solutions. Topical ophthalmic formulations have employed cyclodextrins as complexing agents to improve the solubility (97). Topical application of piroxicam $(0.5 \%, \mathrm{wt} / \mathrm{vol})$ eye drops was found to be effective in reducing aqueous $P G F_{2 \alpha}$ levels in experimental uveitis in rabbits (98). Pre-treatment with topical piroxicam $(0.5 \%$, wt/vol $)$ in glaucoma patients undergoing argon trabeculoplasty effectively inhibited ocular $\mathrm{PGE}_{2}$ synthesis (99). Topical piroxicam $(0.5 \%$, wt $/ \mathrm{vol})$ was also found to possess ocular antiinflammatory activity comparable to diclofenac sodium
$(0.1 \%, \mathrm{wt} / \mathrm{vol})$ and indomethacin $(0.1 \%, \mathrm{wt} / \mathrm{vol})$, and ocular tolerance better than diclofenac sodium (0.1\%, wt/vol) (100).

To improve the ocular delivery of piroxicam, nanosuspensions were prepared using Eudragit RS100 as the polymer (101). The prepared nanosuspension was found to release the drug by diffusion. In endotoxin induced uveitis model, the nanosuspension provided a significant inhibition of inflammation compared with a microsuspension of drug alone.

\section{CONCLUSIONS}

A number of NSAIDs have been formulated as aqueous solutions for ocular delivery using sodium, potassium, tromethamine and lysine salts or complexing with cyclodextrins/ solubilizer to improve aqueous solubility. Ocular penetration of NSAID demands an ophthalmic solution of acidic $\mathrm{pH}$ which could precipitate the drug or increase its ocular irritation potential and cyclodextrins could solve both the problems. The incompatibility of NSAID with benzalkonium chloride, a cationic preservative, commonly used in eye drops, is avoided using polysorbate 80 , cyclodextrins or tromethamine. Lysine salts and $\alpha$-tocopheryl polyethylene glycol succinate disrupt corneal integrity; solubilizers are irritating, hence caution is needed in their use. Thus a nonirritating ophthalmic solution of NSAID could be formulated by dissolving an eye-friendly water soluble salt, cyclodextrin or tromethamine and an antioxidant, if needed, in mildly acidified purified water, if stability permits, with or without benzalkonium chloride. In case of a drug that is insoluble in water, cyclodextrin or tromethamine could be used as solubilizer. Polyvinyl alcohol appears to be a good viscolizer. Amide prodrugs appear to be efficacious for some NSAIDs while ineffective for others due to incomplete hydrolysis in intraocular tissue. Suspension and ocular inserts appear to be irritating to inflamed eye. Oil drop formulation could be considered as a suitable option for water insoluble drugs while ointment for sustained effect. Colloidal nanoparticle formulations are most promising for ocular delivery. As topical ocular anti-inflammatory agent, bromfenac, the most potent COX-2 inhibitor holds promise. Nanoparticle formulations of bromfenac could be tried for topical delivery to the eye.

\section{REFERENCES}

1. J. Harry, and G. Mission. Clinical Ophthalmic Pathology, Principles of Diseases of the Eye and Associated Structures, Butterworth Heinemann, Oxford, UK, 2001.

2. J. H. Chang, and H. Chung. Non-steroidal anti-inflammatory drug and endotoxin induced uveitis. Korean. J. Ophthalmol. 7:35-42 (1993).

3. J. Polansky, and R. Weinreb. Steroids as anti-inflammatory agent. In M. Sears (ed.), Pharmacology of the Eye, Springer, New York, 1984, pp. 460-583.

4. M. Raizman. Corticosteroid therapy of eye diseases; fifty years later. Arch. Ophthalmol. 114:1000-1001 (1996).

5. L. Waterbury, E. A. Kunysz, and R. Bewerman. Effect of steroidal and non steroidal anti-inflammatory agents on corneal wound healing. J. Ocul. Pharmacol. 3:43-54 (1987).

6. R. Schalnus. Topical nonsteroidal anti-inflammatory therapy in ophthalmology. Ophthalmologica 217:89-98 (2003). 
7. B. M. Bandare, P. R. Sankaridurg, and M. D. Willcox. Nonsteroidal anti-inflammatory agents decrease bacterial colonization of contact lenses and prevent adhesion to human corneal epithelial cells. Curr. Eye Res. 29:245-251 (2004).

8. Y. Rojanasakul, and J. R. Robinson. Transport mechanisms of the cornea: characterization of barrier permselectivity. Int. J. Pharm. 55:237-246 (1989).

9. M. Gupta, and D. K. Majumdar. Effect of concentration, $\mathrm{pH}$ and preservatives on in vitro transcorneal permeation of ibuprofen and flurbiprofen from non-buffered aqueous drops. Indian J. Exp. Biol. 35:844-849 (1997).

10. M. Ahuja, A. S. Dhake, and D. K. Majumdar. Effect of formulation factors on in vitro permeation of diclofenac from experimental and marketed aqueous eye drops through excised goat cornea. Yakugaku Zasshi 126:1369-1375 (2006).

11. M. B. Abelson, S. I. Butrus, G. H. Kliman, D. L. Larson, E. J. Corey, and L. M. Smith. Topical arachidonic acid: a model for screening anti-inflammatory agents. J. Ocul. Pharmacol. 3:6375 (1987).

12. A. Regnier, M. Bonnefoi, and F. Lescure. Effect of lysineacetylsalicylate and phenylbutazone premedication on the protein content of secondary aqueous humor in the dog. Res. Vet. Sci. 37:26-29 (1984).

13. S. R. Guimaraes-Filho, C. J. Simal, and H. G. Almeida. Comparison of the anti-inflammatory effects of topically applied aspirin and indomethacin following photocoagulation of the rabbit iris. Braz. J. Med. Biol. Res. 25:67-73 (1992).

14. G. Ciprandi, S. Buscaglia, M. Tosca, and G. W. Canonica. Topical acetylsalicylic acid in the treatment of allergic pollinosic conjunctivitis. J. Investig. Allergol. Clin. Immunol. 2:15-18 (1992).

15. R. Blakytny, and J. J. Harding. Prevention of cataract in diabetic rats by aspirin, paracetamol (acetaminophen) and ibuprofen. Exp. Eye Res. 54:509-518 (1992).

16. S. K. Gupta, S. Joshi, R. Tandon, and P. Mathur. Topical aspirin provides protection against galactosemic cataract. Indian $J$. Ophthalmol. 45:221-225 (1997).

17. M. Voigt, M. Kralinger G. Kieselbach, et al. Ocular aspirin distribution: a comparison of intravenous, topical, and coulombcontrolled iontophoresis administration. Invest. Ophthalmol. Vis. Sci. 43:3299-3306 (2002).

18. C. S. Sweetman. Martindale: The Complete Drug Reference, 34th edn. Pharmaceutical Press, London, 2005.

19. L. I. Kahanne, J. Bogi, A. Farkas, F. H. Tudos, and G. Imre. Indosol - a nonsteroidal anti-inflammatory drug with therapeutic efficacy. Acta Pharm. Hung. 64:125-129 (1994).

20. N. Vulovic, M. Primorac, M. Stupar, and J. L. Ford. Some studies into the properties of indomethacin suspensions intended for ophthalmic use. Int. J. Pharm. 55:123-128 (1989).

21. P. Chetoni, L. Panichi, S. Burgalassi, U. Bendli, and M. F. Seattone. Pharmacokinetics and anti-inflammatory activity in rabbits of a novel indomethacin ophthalmic solution. J. Ocul. Pharmacol. Ther. 16:363-372 (2000).

22. E. Dimitrova, S. Bogdannova, M. Mitcheva, I. Tanev, and V. E. Minko. Development of model aqueous ophthalmic solution of indomethacin. Drug Dev. Ind. Pharm. 26:1297-1301 (2000).

23. D. R. Sanders, B. Goldstick, C. Kraff, R. Hutchins, M. S. Bernstein, and M. A. Evans. Aqueous penetration of oral and topical indomethacin in humans. Arch. Ophthalmol. 101: 1614 (1983).

24. S. Muchtar, M. Abdulrazik, J. Frucht-Pery, and S. Benita. Ex vivo permeation study of indomethacin from a submicron emulsion through albino rabbit cornea. J. Control. Release 44:55 (1997).

25. P. Calvo, J. L. Vila-Jato, and M. J. Alonso. Comparative in vitro evaluation of several colloidal systems, nanoparticles, nanocapsules and nanoemulsions as ocular drug carriers. J. Pharm. Sci. 85:530-536 (1996).

26. P. Calvo, M. J. Alonso, J. L. Vila-Jato, and J. R. Robinson. Improved ocular bioavailability of indomethacin by novel ocular drug carriers. J. Pharm. Pharmacol. 48:1147-1152 (1996).

27. J. Balasubramaniam, S. Kant, and J. K. Pandit. In vitro and in vivo evaluation of the gelrite gellan gum-based ocular delivery system for indomethacin. Acta Pharm. 53:251-261 (2003).
28. J. K. Pandit, S. L. Harikumar, D. N. Mishra, and J. Balasubramaniam. Effect of physical cross-linking on in vitro and ex vivo permeation of indomethacin from polyvinyl alcohol ocular inserts. Indian J. Pharm. Sci. 65:146-151 (2003).

29. M. T. Kumar, C. Rajeshwari, J. Balasubramaniam, and J. K. Pandit. In vitro and in vivo characterization of scleral implants of indomethacin. Drug Deliv. 10:269-275 (2003).

30. J. Balasubramaniam, M. T. Kumar, J. K. Pandit, and S. Kant. Gellan -based scleral implants of indomethacin: in vitro and in vivo evaluation. Drug Deliv. 11:371-379 (2004).

31. J. A. Balfour and S. P. Clissold. Bendazac lysine. A review of its pharmacological properties and therapeutic potential in the management of cataracts. Drugs 39:575-596 (1990).

32. W. Lund. The Pharmaceutical Codex: Principles and Practice of Pharmaceutics, Pharmaceutical Press, London, 1994.

33. O. Reer, T. K. Bock, and B. W. Muller. In vitro corneal permeability of diclofenac sodium in formulations containing cyclodextrins compared to the commercial product Voltaren ophtha. J. Pharm. Sci. 83:1345-1349 (1994).

34. L. Baydoun, and C. C. Muller-Goymann. Influence of noctenylsuccinate starch on in vitro permeation of sodium diclofenac across excised porcine cornea in comparison to voltaren ophtha. Eur. J. Pharm. Biopharm. 56:73-79 (2003).

35. S. Desai, R. Bawa, inventors. Alcon Laboratories Inc., assignee. Topical ophthalmic acidic drug formulations. US Patent 5558 876. September 24, 1996.

36. A. C. Guidera, J. I. Luchs, and I. J. Udell. Keratitis, ulceration and perforation associated with topical non-steroidal antiinflammatory drugs. Ophthalmology 108:936-944 (2001).

37. S. L. Hargrave, J. C. Jang M. E. Fini. Possible role of the vit E solubilizer in topical diclofenac on matrix metallo proteinase expression in corneal melting. Ophthalmology 109:343-350 (2002).

38. M. Ahuja, S. K. Sharma, and D. K. Majumdar. In vitro corneal permeation of diclofenac from oil drops. Yakugaku Zasshi 127:1739-1745 (2007).

39. J. D. Quintana-Hau, E. Cruz-Olmos, M. I. Lopez-Sanchez, et al. Characterization of the novel ophthalmic drug carrier Sophisen in two of its derivatives: 3A Ofteno and Modusik-A Ofteno. Drug Dev. Ind. Pharm. 31:263-269 (2005).

40. V. Sankar, K. Chandrasekaran, S. Durga, et al. Formulation and stability evaluation of diclofenac sodium ophthalmic gels. Indian J. Pharm. Sci. 6:473-476 (2005).

41. V. Sankar, A. K. Chandrasekaran, S. Durga, et al. Design and evaluation of diclofenac sodium ophthalmic inserts. Acta Pharm. Sciencia 48:5-10 (2006).

42. M. Hornof, W. Weyenberg, A. Ludwig, and A. BernkopSchnurcha. Mucoadhesive ocular insert based on thiolated poly acrylic acid): development and in vivo evaluation in humans. $J$. Control Rel. 89:419-428 (2003).

43. K. X. Sun, A. P. Wang, L. J. Huang, R. C. Liang, and K. Liu. Preparation of diclofenac sodium liposomes and its ocular pharmacokinetics. Yaо Хие Хие Baо 41:1094-1098 (2006).

44. A. Guzman, F. Yuste, R. A. Toscano, J. M. Young, A. R. HornVan, and J. M. Muchowski. Absolute configuration of (-)5-benzoyl-1, 2-dihydro-3H-pyrrolo [1, 2-a] pyrrole-1-carboxylic acid, the active enantiomer of ketorolac. J. Med. Chem. 29:589591 (1986)

45. H. P. Sandoval, L. E. CastroDe, D. T. Vroman, and K. D. Solomon. Evaluation of $0.4 \%$ ketorolac tromethamine ophthalmic solution versus $0.5 \%$ ketorolac tromethamine ophthalmic solution after phacoemulsification and intraocular lens implantation. J. Ocular Pharmacol. Ther. 22:251-257 (2006).

46. M. Malhotra, and D. K. Majumdar. In vitro transcorneal permeation of ketorolac tromethamine from buffered and non-buffered aqueous ocular drops. Indian J. Exp. Biol. 35:941-947 (1997).

47. L. Gu, H. S. Chiang, and A. Becker. Kinetics and mechanisms of the autoxidation of ketorolac tromethamine in aqueous solution. Int. J. Pharm. 41:95-104 (1988).

48. M. Malhotra and D. K. Majumdar. Effect of preservative, antioxidant and viscolizing agents on in vitro transcorneal permeation of ketorolac tromethamine. Indian J. Exp. Biol. 4:555-559 (2002). 
49. M. Malhotra, and D. K. Majumdar. In vitro transcorneal permeation of ketorolac from oil based ocular drops and ophthalmic ointment. Indian J. Exp. Biol. 35:1324-1330 (1997).

50. M. Malhotra, and D. K. Majumdar. In vivo ocular availability of ketorolac following ocular instillations of aqueous, oil and ointment formulations to normal corneas of rabbits: a technical note. AAPS PharmSci Tech 6(3):65 (2005).

51. H. E. Kennah, S. Higney, P. E. Laux, J. D. Dorko, and C. S. Barrow. An objective procedure for quantitating eye irritation based upon changes of corneal thickness. Fundam. Appl. Toxicol. 12:258-268 (1989).

52. M. Malhotra, and D. K. Majumdar. Aqueous, oil and ointment formulations of ketorolac: efficacy against prostaglandin E2induced ocular inflammation and safety: a technical note. AAPS PharmSci. Tech. 7(4):96 (2006).

53. P. S. Jayaprakash, C. C. James, N. S. M. G. Rajan, S. Saisivam, and M. Nagarajan. Design and evaluation of ketorolac tromethamine ocuserts. Indian J. Pharm. Sci. 62:334-338 (2000).

54. A. K. Gupta, S. Madan, D. K. Majumdar, and A. Maitra. Ketorolac entrapped in polymeric micelles: preparation, characterization and ocular anti-inflammatory studies. Int. J. Pharm. 209:1-14 (2000).

55. Da. Gamache, G. Graff, M. T. Brady, J. M. Spellman, and J. M. Yanni. Nepafenac a unique non steroidal prodrug with potential utility in the treatment of trauma-induced ocular inflammation: I. Assessment of anti-inflammatory efficacy. Inflammation 24: 357-369 (2000).

56. T. L. Ke, G. Graff, J. M. Spellman, and J. M. Yanni. Nepafenac a unique non steroidal prodrug with potential utility in the treatment of trauma-induced ocular inflammation: II In vitro bioactivation and permeation of external ocular barriers. Inflammation 24:371-384 (2000).

57. M. A. Kapin, J. M. Yanni, M. T. Brady, et al. Inflammationmediated retinal edema in the rabbit is inhibited by topical nepafenac. Inflammation 27:281-291 (2003).

58. F. A. Bucci, L. D. Waterbury, and L. M. Amico. Prostaglandin E2 inhibition and aqueous concentration of ketorolac $0.4 \%$ (Acular LS); and nepafenac $0.1 \%$ (Nevanac) in patients undergoing phacoemulsification. Am. J. Ophthalmol. 144:146-147 (2007).

59. S. S. Lane, S. S. Modi, R. P. Lehman, and E. J. Holland. Nepafenac ophthalmic suspension $0.1 \%$ for the prevention and treatment of ocular inflammation associated with cataract surgery. J. Cataract Refract. Surg. 33:53-58 (2007).

60. D. A. Walsh, H. W. Moran, D. A. Shamblee, et al. Antiinflammatory agents. 3. Synthesis and pharmacological evaluation of 2-amino-3-benzoylphenylacetic acid and analogues. J. Med. Chem. 27:1379-88 (1984).

61. The New Drug Application 020535. The US FDA, Centre for Drug Evaluation and Research Website. Available at: http:// www.fda.gov/cder/foi/nda/97/020535apDuract_chemr_EA. pdf. Accessed October 9th, 2007.

62. E. D. Donnenfeld, E. J. Holland, R. H. Stewart, J. A. Gow, and L. R. Grillone. Bromfenac ophthalmic solution 0.09\% (Xibrom) for postoperative ocular pain and inflammation. Ophthalmology 114:1653-1662 (2007).

63. J. M. Yanni, G. Graff, M. R. Hellberg, inventors. Alcon Laboratories Inc., assignee. Topically administrable compositions containing 3-benzoylphenylacetic acid derivatives for treatment of ophthalmic inflammatory disorders. US Patent 5 475 034. December 12, 1995.

64. L. D. Waterbury, D. Silliman, and T. Jolas. Comparison of cyclooxygenase inhibitory activity and ocular anti-inflammatory effects of ketorolac tromethamine and bromfenac sodium. Curr. Med. Res. Opin. 22:1133-1140 (2006).

65. T. Ogawa, T. Sakaue, T. Terai, and C. Fukiage. Effects of bromfenac sodium, non steroidal anti-inflammatory drug on acute ocular inflammation. Nippon Gakka Gakkai Zasshi 99:406-411 (1995).

66. C. Bucolo, and A. Spadaro. Pharmacological evaluation of antiinflammatory pyrrole-acetic acid derivative eye drops. J. Ocul. Pharmacol. Ther. 13:353-361 (1997).

67. W. Martin, G. Koselowske, H. Toberich, T. Kerkmann, B. Marigold, and J. Augustin. Pharmacokinetics and absolute bioavailability of ibuprofen after oral administration of ibuprofen lysine in man. Biopharm. Drug Dispos. 11:265-278 (1990).

68. S. R. Chakradhara, R. D. Schoenwald, C. F. Barfknecht, and S. L. Laban. Biopharmaceutical evaluation of ibufenac, ibuprofen and their hydroxyethoxy analogs in the rabbit eye. J. Pharmacokinet. Biopharm. 20:357-388 (1992).

69. L. Baydoun, A. Duvel, R. Daniels, et al. Comparison of different ibuprofen-amino acid compounds with respect to emulsifying and cytotoxic properties. Int. J. Pharm. 274:157-165 (2004).

70. R. Pignatello, C. Bucolo, P. Ferrara, A. Maltese, A. Puleo, and G. Puglisi. Eudragit RS100 nanosuspensions for the ophthalmic controlled delivery of ibuprofen. Eur. J. Pharm. Sci. 16:53-61 (2002).

71. A. A. Van Sorge, P. H. Wijnen, J. L. Van Delft, V. M. W. Bodelier, P. H. Wijnen, and N. J. Van Haeringen. Specificity of flurbiprofen and enantiomers for inhibition of prostaglandin synthesis in bovine iris/ciliary body. Prostaglandins 55:169-177 (1998).

72. A. A. Van Sorge, P. H. Wijnen, J. L. Van Delft, V. M. W. Bodelier, P. H. Wijnen, and N. J. Van Haeringen. Flurbiprofen, S (+) eye drops: formulation, enantiomeric assay, shelf life and pharmacology. Pharm. World Sci. 21:91-95 (1999).

73. D. D. Tang-Liu, S. S. Liu, and R. J. Weinkam. Ocular and systemic bioavailability of ophthalmic flurbiprofen. J. Pharmacokinet. Biopharm. 12:611-626 (1984).

74. K. Masuda, T. Ikari, T. Matsuyama, A. Terashima, Goto Takao, inventors, Kakenyaku Kako Co. Ltd., Japan, assignee. Antiinflammatory ophthalmic solution and process for preparing the same. US patent 4474 811. October 2, 1984.

75. G. Graff, M. R. Hellberg, J. M. Yanni, inventors, Alcon laboratories Inc. assignee. Method of treating ocular inflammatory and angiogenesis-related disorders of the posterior segment of the eye using an amide derivative of flurbiprofen or ketorolac. US patent 6646003. November 11, 2003.

76. R. Pignatello, C. Bucolo, G. Spedalieri, A. Maltese, and G. Puglisi. Flurbiprofen-loaded acrylate polymer nanosuspensions for ophthalmic application. Biomaterials 23:3247-3255 (2002).

77. E. Vega, M. A. Egea, O. Valls, M. Espina, and M. L. Garcia. Flurbiprofen loaded biodegradable nanoparticles for ophthalmic administration. J. Pharm. Sci. 95:2393-2405 (2006).

78. P. S. Kulkarni, and B. D. Srinivasan. Anti-inflammatory effects of ketoprofen in rabbit corneal epithelial wound model. Exp. Eye Res. 41:267-73 (1985).

79. M. J. Nachajski, and M. M. Zgoda. Selected Rofams as a micellar solubilizers for diclofenac and naproxen in the environment of the standard vehicle for eye drops. Polim. Med. 35:39-47 (2005).

80. S. Spampinato, A. Marino, C. Bucolo, M. Canossa, T. Bachetti, and S. Mangiafico. Effects of sodium naproxen eye drops on rabbit ocular inflammation induced by sodium arachidonate. $J$. Ocul. Pharmacol. 7:125-133 (1991).

81. C. Bucolo, and A. Spadaro. Effect of sodium naproxen on inflammatory response induced by anterior chamber paracentesis in the rabbit. J. Pharm. Pharmacol. 47:708-712 (1995).

82. P. Russo, V. Papa, S. Russo, et al. Topical nonsteroidal antiinflammatory drugs in uncomplicated cataract surgery: effect of sodium naproxen. Eur. J. Ophthalmol. 15:598-606 (2005).

83. V. Papa, G. Milazzo, M. Santacono, et al. Naproxen ophthalmic solution to manage inflammation after phacoemulsification. $J$. Cataract Refract. Surg. 28:321-327 (2002).

84. C. Bucolo, and A. Maltese. Pharmacological profile of oxaprozin eye drops. J. Ocul. Pharmacol. Ther. 18:75-81 (2002).

85. Z. Liu, J. Li, S. Nie, H. Guo, and W. Pan. Effects of Transcutol $\mathrm{P}$ on the corneal permeability of drugs and evaluation of its ocular irritation of rabbit eyes. J. Pharm. Pharmacol. 58:45-50 (2006).

86. C. Torron, E. Ferrer, O. Ruiz-Moreno, et al. Effect of topical pranoprofen on the lipoxygenase metabolism of the arachidonic acid in endotoxin-induced uveitis. Arch. Soc. Esp. Oftalmol. 75:377-382 (2000).

87. I. Akyol-Salman, D. Lece-Sertoz, and O. Baykal. Topical pranoprofen $0.1 \%$ is as effective anti-inflammatory and analgesic agent as diclofenac sodium $0.1 \%$ after strabismus surgery. J. Ocul. Pharmacol. Ther. 23:280-283 (2007). 
88. T. Ogawa, K. Ohara, and H. Shimizu. Effects of pretreatment with mydriatics on intraocular penetration of $0.1 \%$ pranoprofen. Jpn. J. Ophthalmol. 37:47-55 (1993).

89. K. Ogata, Y. Yamamoto, Y. Ozake, inventors, Yoshitomi Pharmaceutical Industries, Ltd.; Senju Pharmaceutical Co. Ltd., Japan, assignee. Ophthalmic pranoprofen compositions. US patent 4607 038. August 19, 1986.

90. K. Doi, H. Sawa, Y. Ozaki, Y. Kinurra, inventors. Senju Pharmaceutical Co. Ltd.; Yoshitomi Pharmaceutical Industries Ltd., Japan, assignee. Method for stabilizing pranoprofen and stable liquid preparation of pranoprofen. US patent 5856345 . January 5, 1999.

91. S. Miyagi, Y. Horibe, inventors. Santen Pharmaceutical Co. Ltd., Japan, assignee. Pranoprofen eye drops containing organic amine. US patent 6281224 B1. August 8, 2001.

92. T. S. Wood, R. H. Stewart, R. W. Bowman, J. P. McCulley, and T. A. Reaves Jr. Suprofen treatment of contact lens-associated giant papillary conjunctivitis. Ophthalmology 95:822-826 (1988).

93. B. P. Lee, A. Kupferman, and H. M. Leibowitz. Effect of suprofen on corneal wound healing. Arch. Ophthalmol. 103:9597 (1985).

94. H. M. Leibowitz, W. J. Ryan, A. Kupferman, and L. DeSantis. Bioavailability and corneal anti-inflammatory effect of topical suprofen. Invest. Ophthalmol. Vis. Sci. 27:628-631 (1986).

95. D. A. Ward. Comparative efficacy of topically applied flurbiprofen, diclofenac, tolmetin, and suprofen for the treatment of experimentally induced blood-aqueous barrier disruption in dogs. Am. J. Vet. Res. 57:875-878 (1996).
96. S. H. Gerson, W. H. Wesley, inventors, Alcon Laboratories Inc., assignee.(+)-Suprofen esters and amides as ophthalmic antiinflammatory agents. US patent 5013 751.May 7, 1991.

97. I. Ahmed, inventor, Pfizer Inc., assignee. Ophthalmic piroxicam solution. US patent 5362 758. November 8, 1994.

98. M. De Bernardi, A. Tafi, D. Mazzacane, G. Zennaro, E. Bozzo Costa, and S. Contos. Effects of topical treatment with piroxicam on prostaglandin synthesis in experimental uveitis. Int. J. Tissue React. 9:361-364 (1987).

99. M. T. Dorigo, D. Doro, and A. Cecchinato. Aqueous prostaglandin E2 and intraocular pressure after argon laser trabeculoplasty in glaucoma patients pretreated with topical piroxicam. Int. J. Tissue React. 9:73-75 (1987).

100. D. Costin, S. Popa, and C. Costea. Clinical study on the tolerance and efficacy of piroxicam used in cataract surgery, compared with diclofenac and indomethacin. Rev. Med. Chir Soc. Med. Nat. Iasi 109:305-313 (2005).

101. K. Adibkia, S. M. R. Siahi, A. Nokhodchi, et al. Piroxicam nanoparticles for ocular delivery: physicochemical characterization and implementation in endotoxin-induced uveitis. J. Drug Target 15:407-416 (2007).

102. A. C. Moffat, M. D. Osselton, B. Widdop, and L. Y. Galichet. Clarke's Analysis of Drugs and Poisons, 3rd edn. Pharmaceutical Press, London, 2004.

103. The New Drug Application 020776. The US FDA, Centre for Drug Evaluation and Research Website. Available at: http:// www.fda.gov/cder/foi/label/2002/18841s12s16lbl.pdf. Accessed December 8th, 2007. 